Vol. XIV, No. 4

\title{
Notes on a Trip to Saskatchewan September, 1956
}

\author{
F. W. KENT, Iowa City, Iowa
}

To one interested in birds, the outdoors and photography, a natural area different from one's' own is much more attractive than a commercialized resort. So, when the chance came for me to visit Saskatchewan I was delighted. I had long wanted to see the "Prairie Provinces" and I very much enjoyed my short visit to even a small part of the interesting country. The wheat fields proved more extensive, the towns more modern, and the "pot-holes" less wild than I expected, but the atmosphere of the open country, the absence of ads cluttering the highways, the heavy freight on the rails instead of on the roads, and the friendliness of the people made our trip a real treat.

After travelling through several hundred miles of perfectly flat country our group was caught by surprise when we dropped into the Qu'Appelle Valley with its undulating ridges and brilliant fall foliage. We spent a couple of days fifteen miles up river from Fort Qu'Appelle in perfect fall weather. I spent much of the time in a canoe exploring the shores and marshes, photographing the scenery and any birds I could approach. At one place where the canoe had caught on a shallow mud bar I was soon surrounded by several hundred Dowitchers, twittering all the time in a quiet melodious way as they fed. Some tucked their long bills back under their feathers and slept, and all of them were quite unconcerned about my presence. Although commonplace here, no doubt, the large numbers of Franklin's Gulls were a new experience to me as they moved up lake in the morning and down lake at dusk in well-ordered flocks,

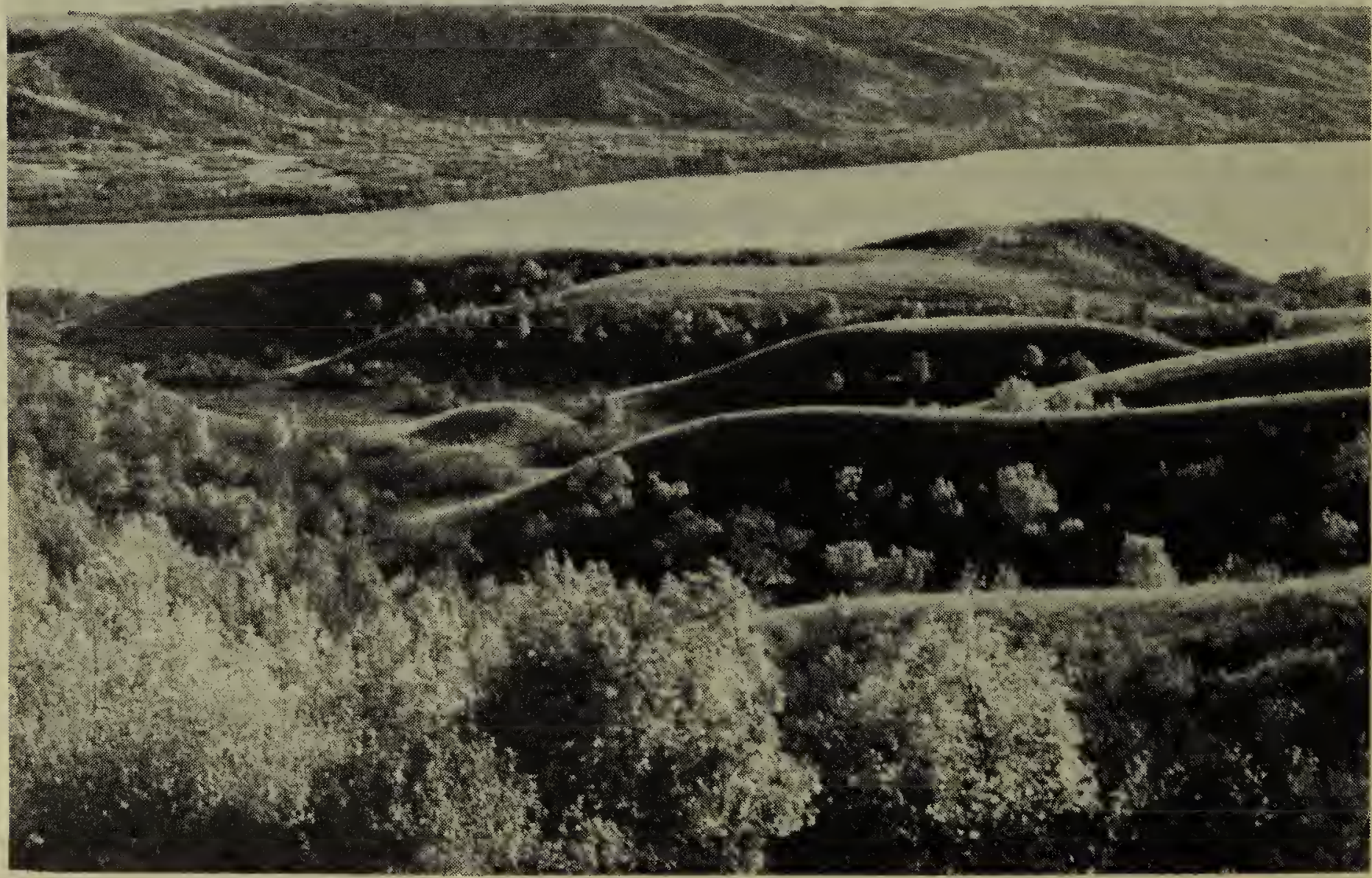

Photo by F. W. Kent

Qu'Appelle Valley, Saskatchewan 


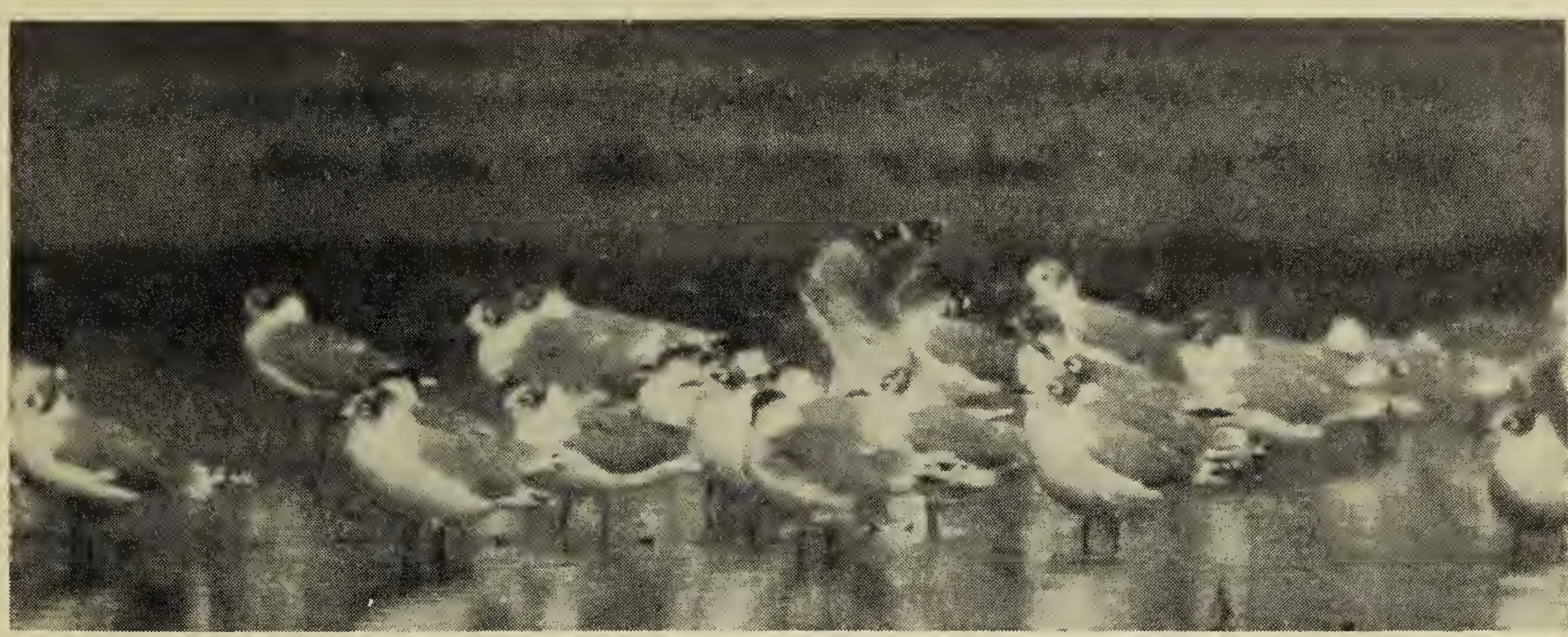

Photo by F. W. Kent

Franklin's Gulls in the Qu'Appelle Valley

resting on bars in mid-day. Large flocks of the same birds were seen in North Dakota feeding over the fields late in the day. This gull is a species which is seen in Iowa. only in the spring in very small numbers. Of the ducks, the Blue-winged Teal is a very common migrant in Iowa, but not so common there is the Canvas-back which was the big duck that I saw most frequently in the Qu'Appelle. I expected to find a larger variety of ducks, but probably I was seeing mostly resident species. I could fancy what an interesting area this would be in the spring and nesting season.

The grebes, Western and Horned, and the Pelican are birds which we see in Iowa only rarely or as stragglers, so it was nice to watch numbers of them. I was curious about a couple of young Westerns still being fed by an adult. It seemed late in the season for young birds, September 15.

One day spent in Regina gave us the opportunity to visit the Museum - the exterior and grounds so admirably conceived to fit that region, the habitat groups so suitable and lively, and especially well done, the ecological and educational panels.

While we sampled only a small bit of that vast area we came away admiring it and hoping to return. In fact, we discussed plans for another visit most of the 1300 miles back to Iowa.

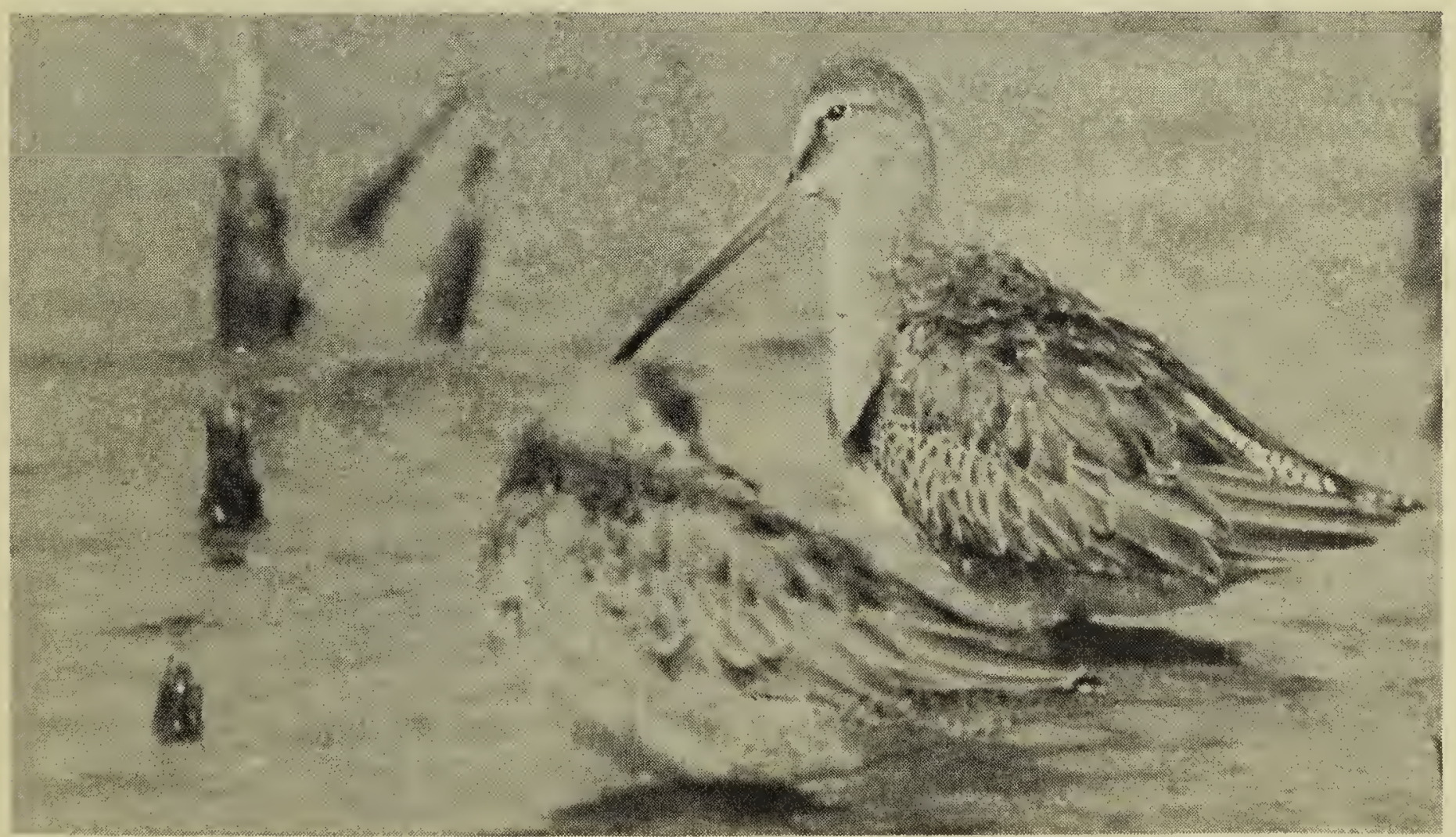

Photo by F. W. Kent

Dowitchers at rest 